“... while public awareness of the gay, lesbian, and bisexual civil rights movement is growing, the average person knows very little about the psychological condition of gender identity disorder and the process of sex reassignment." 


\section{TRANS-ACTION FEES}

\section{Public Insurance, Medical Necessity, and Sex Reassignment Surgery}

DUE TO A GENERAL LACK OF UNDERSTANDING REGARDING TRANSGENDER PERSONS, THIS GROUP OF INDIVIDUALS IS PUT AT PARTICULAR RISK OF DISCRIMINATION IN THE AREA OF LAW AND MEDICINE. THE QUESTION OF PUBLIC INSURANCE COVERAGE FOR MEDICAL TREATMENT OF GENDER IDENTITY DISORDER IS ONE OF THE MOST PRESSINC ISSUES IN THIS FIELD. THIS PAPER WILL PROVIDE AN OVERVIEW OF TRANSGENDERISM AND TREATMENTS OF GENDER IDENTITY DISORDER IN ORDER TO ASSESS THE MEDICAL NECESSITY OF SEX REASSIGNMENT SURGERY AND OTHER PROCEDURES PROVIDED TO TRANSGENDER PERSONS. WHILE MEDICAID GUIDELINES DO ALLOW FOR THE DENIAL OF MEDICALLY NECESSARY SERVICES, THESE DENIED SERVICES MUST FIT CERTAIN CRITERIA. SPECIFIC CASES IN WHICH STATE INSURANCE COVERAGE WAS PERMITTED OR DENIED TO TRANSGENDER MEDICAID PATIENTS WILL BE EXAMINED IN ORDER TO ASSESS THE OVERALL ETHICALITY OF MEDICAID POLICY TOWARDS TRANSGENDER PERSONS. 


\section{DISCRIMINATION AND THE}

\section{TRANSGENDER COMMUNITY}

Transgender persons are part of a fast-emerging but historically understudied group. Lack of understanding regarding the transgender community is reflected in local, state, and federal laws, under which transgender persons have limited rights. Many anti-discrimination laws that have already been extended to include sexual orientation continue to ignore gender identity and expression. Similarly, while public awareness of the gay, lesbian, and bisexual civil rights movement is growing, the average person knows very little about the psychological condition of gender identity disorder and the process of sex reassignment. The combination of neglect and ignorance surrounding transgender issues, when viewed from the perspectives of medicine and law, presents the possibility of abuse and discrimination of transgender patients' rights to receive insurance coverage for medical treatment surrounding their condition.

The medical procedures involved in changing one's gender, especially sex reassignment surgery, are particularly unfamiliar because the topic is often regarded as taboo. Private insurance companies do not provide coverage for such procedures because they consider them to be elective. This paper will not address the issue of private insurance companies' policies because these procedures are nearly always categorically excluded in private contracts. ${ }^{\text {iii }}$ However, examining the funding policies of governmentrun programs such as Medicare and Medicaid can provide a unique perspective on the ethicality of current regulations regarding insurance coverage.

The objective of this study is to shed light on the process of transitioning frequently undergone by transgender persons in order to determine the appropriateness of current state-run insurance policies toward procedures associated with changing one's gender and sexual identity. This paper will first give an overview of the medical aspects of being transgender and the surgical procedures that often accompany gender transitions in an attempt to assess the medical necessity of sex reassignment surgery (SRS) and other medical treatments associated with gender identity disorder. It will subsequently analyze the status of Medicaid policy as it pertains to SRS and related services as well as the denial of medically necessary services to patients under Medicaid. The cases in which state insurance coverage has been permitted or denied will then be reexamined in light of these findings, and the overall ethicality of these cases and their related policies will be assessed.

\section{THE AMBIGUITIES OF GENDER IDENTITY}

\section{DISORDER:AN OVERVIEW}

Fluid and socially-charged terms such as those surrounding sex and gender are particularly difficult to define. Some of the confusion surrounding transgender identity and the proper treatment of transgender persons can be attributed to the ambiguity regarding gender identity terminology. This section will attempt to illuminate some of the problems and definitions of sex and gender as they relate to transsexuality.

\section{GENDER IDENTITY DISORDER AND TRANS- SEXUALITY}

Transgender and transsexual are terms used to describe some people with the psychological condition known as Gender Identity Disorder (GID). The psychological diagnosis of GID is often accompanied by physical ramifications, but not all persons with GID feel the need to surgically alter their bodies to physically match the bodies of their target sex. ${ }^{i v}$ As such, this paper will use the term "transgender" as an umbrella term encompassing all those persons who were assigned a gender at birth that differs from their internal gender identity (target gender). The term "transsexual" will only be used in reference to those persons undergoing SRS.

The Diagnostic and Statistical Manual of Mental Disorders (DSM-IV), generally regarded as the bible of psychological diagnosis, describes individuals with GID as those who have "a strong and persistent identification with the opposite gender. There is a sense of discomfort in their own 
gender and may feel they were 'born the wrong sex.'" addition, GID is a particularly sensitive diagnosis because it is often, though not always, diagnosed in conjunction with depression and suicidal thoughts. vi The lingering effects of these other afflictions could distort assessments of the efficacy of SRS, an issue that needs to be taken into account when the medical necessity of SRS is assessed.

PREVALENCE OF TRANSGENDER PERSONS

Estimates regarding the prevalence of transgender persons range from $\mathrm{I}$ in $\mathrm{II}, 900$ to $\mathrm{I}$ in 37,000 for assigned males and $\mathrm{I}$ in 30,400 to $\mathrm{I}$ in 107,000 for assigned females. vii It must be noted, however, that many self-identified transgender individuals are not professionally diagnosed, do not undergo surgery, or deal with their transgender identity in alternative ways (such as cross-dressing), which makes accurate statistics assessing the pervasiveness of transgender persons difficult to acquire. viii $^{\text {iil }}$

TRANSSEXUALITY IN THE COURTS

The term transsexual, as defined by the DSM-IV diagnosis of GID, can describe individuals at any stage in the transition process (before, during, or after hormones and surgical procedures). In spite of this, where the law is concerned the exact operative state of a transgender individual is often a necessary detail. Some court cases have allowed the use of the "he" pronoun to describe a pre-operative or mid-operative female-to-male transsexual, or the "she" pronoun for a transitioning male-to-female transsexual.ix When the sex of the individual is an integral part of the issue at hand in the trial, however, courts generally do not recognize the gender transition as having taken place until the genitals of the person have been altered, or, in other words, until the individual has undergone SRS. ${ }^{x}$ Persons who do not desire SRS cannot, despite their gender identity and outward gender expression, be considered a member of that gender. Massachusetts General Law, for example, holds that birth certificates can be amended to reflect new gender identity, but only providing the person has completed sex reassignment surgery. ${ }^{x i}$ Even if, in all other respects, the person appears to be the opposite gender, most courts follow

\section{"The ... DSM-IV ... describes individuals with GID as those who have...} 'a sense of discomfort in their own gender and may feel they were "born the wrong sex." ""

Massachusetts and still regard the individual as officially his or her originally assigned sex until SRS is complete.xii This can create problems for individuals who, for instance, wish to claim discrimination based on sex but have not completed male-to-female SRS, and thus cannot qualify as female in the courts. This problem creates a legal necessity for SRSxiii that will be returned to further on in the assessment of Medicaid funding for SRS.

\section{AN OVERVIEW OF SRS PROCEDURES}

The Harry Benjamin International Gender Dysphoria Association's Standards Of Care For Gender Identity Disorders (hereafter known as Standards of Care or SOC) provides an in-depth outline, for both patients and therapists, of the suggested approach for treating patients with GID. A brief overview of the methods and procedures will be outlined here in order to demonstrate the extensive process involved in undergoing a sex change. By showing the vast array of criteria one must fulfill before obtaining SRS, this section will challenge the claim that SRS and related medical procedures are often performed whimsically. ${ }^{x i y}$ The process is broken into three distinct phases, although SOC acknowledges that fulfillment of all three stages is not appropriate for all patients, and some will be satisfied with completion of one or two phases, rendering complete SRS unnecessary.xv 


\section{THE FIRST PHASE: PSYCHOTHERAPY}

While SOC acknowledges that psychotherapy is not necessary in all cases, it is certainly highly recommended for patients who wish to undergo SRS in order to provide options and assess eligibility and readiness for the life adjustments involved in sex change. Psychotherapy also addresses the effects of GID on the patients' work, education, and family life.xvi There is no required number of sessions of psychotherapy because patients vary greatly in emotional state and psychological history, and SOC wishes to avoid patients seeing psychotherapy as simply a hurdle on their way towards their ultimate goal of SRS. xvii

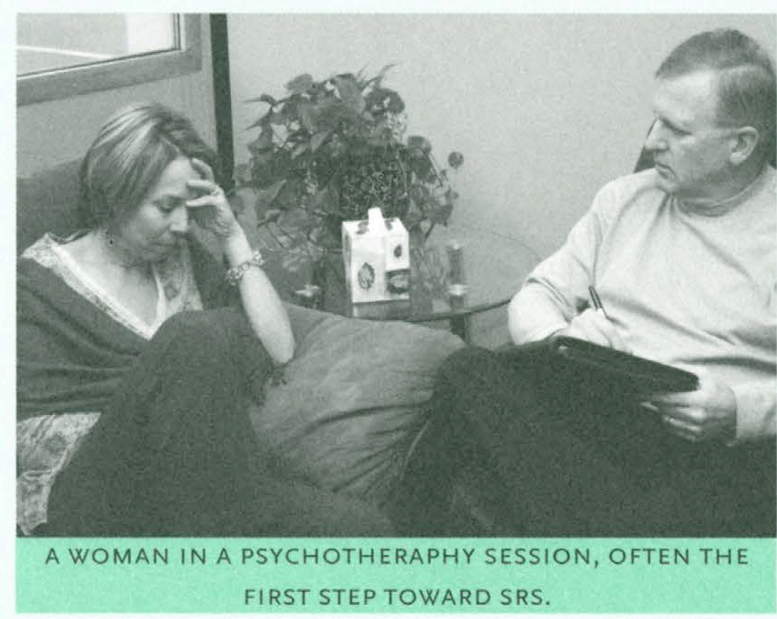

During psychotherapy the therapist encourages the patient to experiment with brief forays into the world of the opposite sex through cross-dressing as well as basic cosmetic alterations such as the removal of facial hair for men or breast-binding for women. ${ }^{\text {xiii }}$ In order to proceed to the second stage of hormone treatment, a patient must meet several criteria. "Without first meeting these recommended eligibility requirements," SOC explains, "the patient and the therapist should not request hormones or surgery."xix These criteria should be indicated in a documentation letter written by the mental health professional. They include evidence that the patient is fully aware and has been counseled on the effects of hormones, and that he or she is over eighteen years of age and has either lived for three months as the opposite gender or has undergone a sufficient amount of psychotherapy (also usually three months). ${ }^{x x}$ In addition, the patient must demonstrate that he or she is ready to continue the process in a responsible manner by showing he or she has made progress overcoming other identified problems such as alcoholism or suicidal tendencies. ${ }^{\mathrm{xxi}}$

THE SECOND PHASE: HORMONE TREATMENT

Once the patient's eligibility and readiness is assessed, he or she qualifies for hormone treatment. Biological males are treated with estrogen in order to allow breast growth, increase body fat and curviness, decrease body hair, and shrink the testicles. Biological females treated with testosterone experience a decrease in breast mass, increased body weight and upper body strength, increase in facial and body hair, and enlarging of the clitoris. ${ }^{x x i i}$ In essence, the patient undergoes a "psychologically unbalancing" or "second puberty." xxiii For biological females, a mastectomy can be performed during this stage along with the hormone treatments. xxiv It is usually necessary for hormone treatment to continue for two years before its full effects are realized, and patients generally must continue treatment throughout their lives to maintain the desired effects. $x x y$

At least one year of this two-year period is also required for the individual, if he or she desires, to pass to the subsequent and final stage of gender reassignment. More assessment and psychotherapy is necessary, Sultan explains, because the treating physician must be certain that the gender dysphasia is real and that "[t]he disorder is not a symptom of another mental disorder"; that is, that the person genuinely has deep-seated, irreversible issues with his gender and that the feelings of dysphasia are not manifestations of paranoia, schizophrenia, or other afflictions. ${ }^{x x v i}$ 
Requirements for passage into this most drastic phase of sex reassignment are stringent. The $S O C$ requires that the patient live as a member of their target gender and undergo hormone therapy for at least twelve continuous months prior to undergoing SRS. In addition, he or she must be completely aware of the financial burdens, hospitalizations, and possible risks and side effects associated with SRS and must obtain a competent sex reassignment surgeon. xxvii When all of these requirements are demonstrable, a mental health professional must perform a comprehensive evaluation of him or her and then write a letter describing the patient's condition and mental status as ready for surgery. This letter is required before a surgeon can proceed with SRS, meaning that SRS is not simply an elective procedure. ${ }^{x x v i i i}$

Patients also must be completely aware of all the particulars regarding the surgical process itself. In female-to-male patients, SRS involves a phalloplasty in which a phallus is created from the patient's forearm tissues.xxix Testes are created and attached, and the woman becoming a man generally has a hysterectomy and salpingo-oophorectomy to remove reproductive organs. ${ }^{\mathrm{xxx}}$ Other procedures include a vaginectomy, metoidioplasty (creating a micro penis from the enlarged clitoris by severing connecting tissue ${ }^{x x x}$ ), scrotoplasty, and urethroplasty in order to create a urethra and scrotum.

In male-to-female patients, SRS involves an orchiectomy (removal of the testicles), penectomy, vaginoplasty, clitoroplasty, and labiaplasty.xxxii In essence, "this surgery involves removal of most of the penis and the entire testes, with the remaining penis turned 'inside-out' and then grafted to the newly constructed vaginal opening." xxxiii Labia and a clitoris are then created with excess tissue. For both transformations, several procedures are often necessary in order to obtain full sexual function and coital ability, and occasionally full function is not achieved.xxxiv After SRS, follow-up therapy is often necessary and always

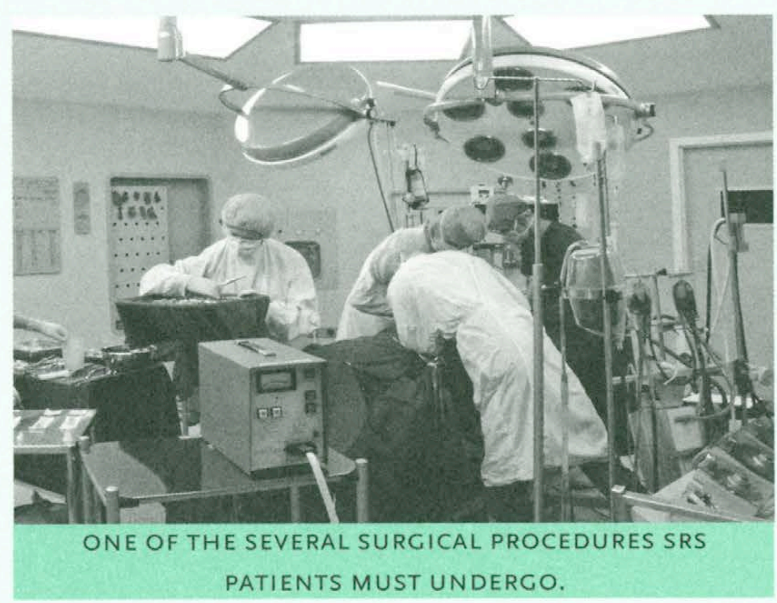

recommended to assess possible long-term medical conditions resulting from SRS and hormone treatment. ${ }^{x x y v}$

As demonstrated by this section, the claim that SRS is performed whimsically and treated as an elective or cosmetic surgery is not supported by evidence, which shows the highly complicated and time-consuming process that transsexual individuals must go through in order to alter their biological sex. The subsequent section will present a brief history and outline of the rules of government-funded medical insurance programs, in an attempt to explain why coverage is so frequently, and often categorically, denied to transgender patients.

\section{THE RULES OF GOVERNMENT-FUNDED HEALTH COVERAGE}

Medicare and Medicaid were both part of programs conceived in the I960s and passed in 1965 as part of the Social Security Act.xxxvi Medicare provides health insurance coverage for retired persons, therefore its role in this paper is minimal. As it is highly unlikely for a person over 65 to begin SRS, conflicts with funding and Medicare are extremely rare.xxxvii Medicaid, on the other hand, provides coverage for the indigent. Before one can adequately address the true issue of funding for SRS under public insurance programs, the history and rules regarding the programs themselves must be understood. 
MEDICAID AND THE LOOPHOLE OF JOINT FEDERAL AND STATE CONTROL

Medicaid, besides having a target user group in a lower age bracket, is a cooperative federal and state program. Both the state and the federal government help to fund Medicaid. The federal government provides the basic regulations and goals of the program, but leaves it to the states to decide exactly which procedures are covered. xxxviii

Medicaid was created by Title XIX of the Social Security Act of I965. ${ }^{\text {xxix }}$ Because it allows the states to create their own programs based off of loose federal regulations, any lawsuits brought against the states must be based on these federal regulations. ${ }^{\mathrm{xl}}$ The preamble of Title XIX designates the intended recipients of Medicaid to be those who cannot afford "medically necessary" services, the first of a plethora of vague terms used to describe the functions of Medicaid, including requirement that standards be "reasonable," "consistent with the objectives" of Title XIX and the services covered must "reasonably achieve the purpose" of the services. ${ }^{x l i}$ States must create a program that is in the best interest of Medicaid recipients, and one that has a method of reviewing claims to ensure that appropriate claims are funded. One slightly less ambiguous aspect of the statute is the prohibition of discrimination or preclusion of funding based solely on the type of illness. ${ }^{\text {lii }}$ Overall, however, the statutes surrounding Medicaid are sufficiently vague to provide a vast array of interpretations of the requirements and role of the states in determining funding for procedures.

\section{NCREASED RESTRICTIONS ON SERVICES}

At the advent of private insurance, Medicare, and Medicaid, insurers relied almost entirely on doctors to determine the necessity of services. Eventually, however, private insurers, and in turn Medicare and Medicaid, realized that they were being charged for procedures that were entirely cosmetic or unnecessary. Private insurers inserted phrases restricting procedures to those considered "medically necessary," but when they continued to lose cases well into the I970s, they began wording their contracts more strictly. Medicaid also inserted statutes forbidding "experimental" and "cosmetic" treatment at this time.

Hall explains that the "experimental treatment" in health insurance policies today responds to a growing concern "that most current medical procedures were adopted without ever having been tested rigorously and that at least some of the procedures commonly used today have limited or no medical value." xliv Likewise, the "cosmetic" exclusion came about as people began to look to medicine for weight loss and plastic surgery.xiv These are two of three chief explanations, medical necessity being the third, that have been used in courts to explain Medicaid's (as well as private insurers') reasons for not funding SRS.

DENIAL OF MEDICALLY NECESSARY PROCEDURES AND THE COST FACTOR

It is important to consider one other aspect of Title XIX before attempting to apply it to SRS. As Finley points out, Congress never defines the term "necessary medical services." xlvi He argues for further investigation into the true meaning of the Medicaid statutes and how they are applicable in an ever-changing, ever more expensive medical world.

Title XIX, Finley argues, is very interested in cost-control and management of resources, and many of the statutes reference this goal. xlvii Unfortunately, state investment in keeping costs down comes directly into conflict with providing all "necessary medical services" as indicated in Section 1396 . "If a state is required to fund all medically necessary services", Finley writes, "other viable objectives-especially those of cost control and state discretion to meet fiscal concerns - will be undercut. Therefore, it is unlikely that Congress intended that a requirement be inferred from section 1396 , since such a construction would be detrimental to other statutory concerns."xlviii In other words, Finley shows that Title XIX does not mandate funding of all medically necessary services, but rather it requires that any limitations on medically necessary services be reasonable. ${ }^{x l i x}$ This means that while medical necessity 
should be the goal of funding, the federal government recognizes that there are other factors in determining the "reasonableness" of claims, such as cost. This limiting objective is indicated in the evolution of Medicaid and the additions Congress made to Title XIX after its inception. It shows that, despite Congress' ambitious intentions regarding the program, the last few decades have brought about expensive advancements in the realm of healthcare, and new Medicaid restrictions must reflect the changing times.

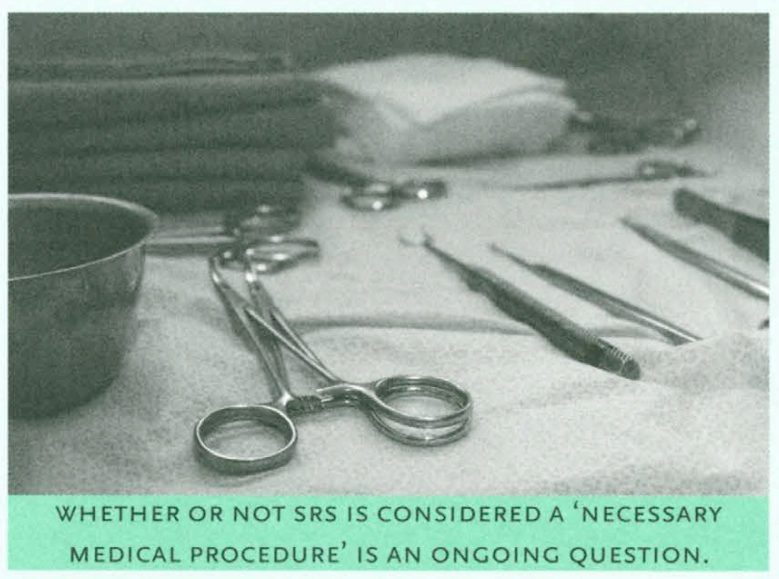

SRS: DO THE RESTRICTIONS APPLY?

While male-to-female transitions are significantly less expensive than female-to-male transitions, (with the former costing between $\$ 18,000$ and $\$ 35,000$ and the latter costing over $\$ 50,000)$ the financial burden associated with SRS is astronomical regardless of the original biological sex of the individual. It is here, in light of the limits agreed upon in the previous section, that the question of insurance coverage for such procedures will be analyzed. While the subject of private insurance coverage for SRS and related procedures is outside the scope of this paper, determinations regarding coverage of such treatments are relevant to both public and private insurance policies. This section will apply relevant data regarding SRS and related procedures to first assess why sex change treatments are neither cosmetic nor experimental, and why they should be consid- ered medically necessary. Once the medical necessity of SRS is assessed, the appropriateness of their coverage under Medicaid policy will be determined.

DEBUNKINC "COSMETIC" AND "EXPERIMENTAL" CLAIMS

Characterizing SRS and related procedures as either cosmetic or experimental was one of the easiest ways for states to get out of paying for SRS. Dasti explains, "While states cannot effect bans on necessary treatments on the basis of diagnosis discrimination, any non-necessary procedure can be barred from coverage by states as they choose." li In other words, by designating a procedure either cosmetic or experimental, they can completely exclude it from their policy without breaking Section I392, which forbids states from discriminating against a particular illness or affliction by categorically denying funding for all treatments associated with that condition.

Medicaid claims that SRS was cosmetic were deflated by G.B. v. Lackner, a Medicaid lawsuit in California in which the judge concluded: "It is clearly impossible to conclude that transsexual surgery is cosmetic surgery." lii Despite the fact that transsexual and transgender surgery results in an altered outward appearance of the individual, it is being used to correct a psychological disorder and should therefore not be considered cosmetic, but a surgery that is correcting an inner default. Kirkland writes that physicians in Lackner responded to the "cosmetic" argument with the "illness" argument: "Unless this person gets sex reassignment surgery such that her genitalia and hormones match her sexual identity, she occupies the legal category of an untreated ill person who is entitled to Medi-Cal benefits." liii The judge in this case also ruled that the surgery was "necessary and reasonable," a fact that is applicable to the subsequent section on medical necessity.

The use of the word "experimental" was also common Medicaid terminology, and one that seems slightly more valid. In the early I970s SRS was relatively new and thus had high risks associated with it. ${ }^{\text {liv }}$ As time passed, 
however, the procedure was improved upon and as early as I976 judges began to rule that this procedure was not ex-

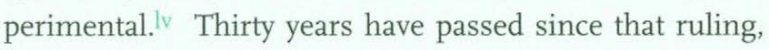
and doctors have made even more progress regarding SRS. It is absurd, therefore, to continue to characterize such a procedure as experimental especially considering the large number of functioning transsexual persons living in society today.

\section{"The extreme social} sacrifices and financial burdens that transgender patients undertake further evidences their faith in the fact that they will benefit from them."

MEDICAL NECESSITY OF SEX REASSIGNMENT PROCEDURES

After determining the reasons that SRS is not to be considered cosmetic or experimental, this paper will now look at its medical necessity. Standards of Care characterizes both hormone treatments and SRS as medically necessary procedures. Regarding hormone treatment, SOC concludes that:

Cross-sex hormonal treatments play an important role in the anatomical and psychological gender transition process for properly selected adults with gender identity disorders. Hormones are often medically necessary for successful living in the new gender. They improve the quality oflife and limit psychiatric co-morbidity, which often accompanies lack of treatment. ${ }^{\text {lvi }}$
In regards to SRS, SOC once again comes down strongly in favor of categorizing the procedure as medically necessary. It reads:

In persons diagnosed with transsexualism or profound GID, sex reassignment surgery, along with hormone therapy and real-life experience, is a treatment that has proven to be effective. Such a therapeutic regimen, when prescribed or recommended by qualified practitioners, is medically indicated and medically necessary. Sex reassignment is not "experimental", "investigational", "elective", "cosmetic", or optional in any meaningful sense. It constitutes very effective and appropriate treatment for transsexualism or profound GID. !vii

As was previously mentioned, patients with GID often suffer from other psychological conditions such as depression, anxiety, and suicidal thoughts. ${ }^{\text {lviii }}$ When the origins of these conditions lay in the patient's incorrect gender identity, they should be assuaged by hormone therapy and SRS. Such conditions could also conceivably be exacerbated, however, by societal rejection and discrimination against transsexual persons. Therefore, assessing the psychological state of post-operative transsexual individuals and using this as a marker to determine the success of the SRS could be a faulty assessment method due to the additional societal pressures assumed when one becomes a member of the opposite sex.

A different, although similarly flawed, method to determine medical necessity is to assess patient satisfaction with their new physical gender. This should only be asked of patients who followed the standards of care recommended by The Harry Benjamin International Gender Dysphoria Association, so as to assure that only properly cared for patients are assessed.

The extreme social sacrifices and financial burdens that transgender patients undertake further evidences their faith in the fact that they will benefit from them. Transsexual individuals who undergo surgery are often 
forced to give up their careers or are ostracized from their families. They also can become unable to bear children, and risk medical problems in the future. It seems such sacrifices would only be made if he or she were completely convinced of the procedure's effectiveness.

An additional vital point that needs to be taken into consideration pertains not necessarily to the phrase "medical necessity" but certainly to the phrase "necessary medical services" as it is used in section I392 of the Title XIX statutes. Early on in this investigation, the difficulties transgender individuals experience in the courts were discussed, in particular, the inability for the courts to determine gender/sex identity for mid-operative or pre-operative persons. As Dasti points out, there is a need for facilitating transsexual surgical procedures in the legal sense because without it laws that follow in society's strict binary-gendered definitions are difficult to apply and enforce. lix "One certainly can hope for a future in which a transgender person can identify as neither fully male nor fully female, yet still be welcome as a full participant in society," Dasti writes. "Until that day, however, the nearly fetishistic focus that the law places on genital structures undergirds a strong argument that access to sex-reassignment surgery is necessary in order to avoid shutting an entire class of citizens outside of the law." |x Dasti presents an additional compelling reason for surgical procedures to be regarded as necessary: without it there would be many more genderambiguous persons, which would make the court's job even more difficult.

Most doctors specializing in treating transgender patients agree that, for some patients with GID, SRS presents the only option for alleviating or curing the psychological condition. Therefore, this paper will proceed from the premise that sex-change operations are medically necessary surgeries. This premise is clearly not a flawless one, and evidence as to the effectiveness of these surgeries is incomplete and certainly warrants further study, but it is generally accepted and has been upheld in several court decisions. ${ }^{\text {lxi }}$
SRS: MEDICALLY NECESSARY, BUT FUNDABLE? The last question that must be addressed in this section is whether SRS falls in the group of medically necessary exceptions - procedures that are deemed vital, but can be refused on the grounds that they are too expensive and would place too great of a burden on the state. Despite the fact that SRS procedures and associated hormone treatments can be very expensive on an individual scale, there are very few sex reassignment surgeries each year. ${ }^{\text {xii }}$ The financial burden that such procedures would place on the state is minimal, therefore denial of such services would not fulfill the statute of a "reasonable" restriction to place on medical care.

\section{CASE HISTORY AND THE CURRENT STATE OF COVERAGE}

In order to continue with the assessment of government funding for treatment procedures, it is helpful to first delineate the options available to government programs regarding the extent of treatment funded by the programs and the levels of funding that are accepted by Medicaid in different states.

POSSIBLE DEGREES OF FUNDINC

There are several paths that government funding of sex change procedures and treatments could take. They will be outlined here in order to provide a basis from which to assess the current state of Medicaid coverage.

i. Fund nothing associated with gender identity disorder;

ii. Provide compensation for only psychotherapy associated with GID;

iii. Compensate psychotherapy and hormone treatment, but not SRS or other surgical procedures;

iv. Compensate for psychotherapy, hormone treatment, and surgical procedures such as mastectomy, but not genital surgery;

v. Compensate for all medical care related to GID, including SRS surgeries, but on a case-by-case basis. 
vi. Compensate for all medical care related to GID, including all SRS surgeries

The first option of providing absolutely no funding is not a realistic public policy, because GID is a diagnosable psychological disorder that is recognized as such by the $D S M-I V$. Funding is certainly provided for psychotherapy associated with other psychological disorders. As Todd Savage explains in an article on the high costs of gender reassignment, even private insurers typically pick up the

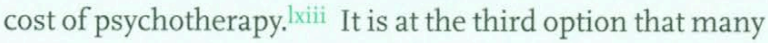
private insurers draw the line. "Doctors are usually able to get reimbursed for hormone treatments," Savage explained, "but only because they are deliberately vague in reporting their purpose." Ixiv It can be concluded that doctors, if they want the insurance company to fund hormone treatment, do not explicitly inform insurers that it is being used as part of treatment for GID. In the world of private insurance, denial of care can also extend to contra-care, or any care that is used in conjunction with SRS, such as prostate exams for male-to-female patients or gynecological care for female-to-male. ${ }^{\text {xv }}$

\section{STATE COVERAGE TRENDS}

Due to the state control of Medicaid, the extent of coverage varies greatly from state to state. There are several states, including California, Minnesota, Washington, and Iowa, that have ruled against categorical denial of all procedures relating to sex change. The court ruled that the denial of Medicaid benefits was arbitrary and "inconsistent with the objectives of the federal Medicaid statute." This does not mean that these states permit funding as per option six, but that they choose option five and will fund some procedures as presented on a case-by-case basis. Ixvi In the case of Iowa and Washington, however, this seems to mean that they will fund hormone treatment and smaller surgical procedure such as mastectomies, but not SRS itself. In addition, Iowa's groundbreaking I980 ruling in Pinneke v. Priesser, in which the judge ruled that SRS was the only method known that would help the plaintiff's transsexuality, xlvii was essentially overturned by Smith v. Ramussen in 2002.
Smith v. Ramussen ruled that Pinneke v. Priesser was superseded by Iowa Human Services Department regulations. ${ }^{\text {xlviii }}$

Most other states, including Alaska, Illinois, and Pennsylvania, still have statutes on their Medicaid policies that categorically exclude procedures relating to transsexuality. Oregon, for example, denied state coverage of sexchange procedures ruling that "there was no good evidence showing that sex-reassignment surgery improves patients' mental and emotional well-being or socioeconomic status or that it reduces the incidence of suicide attempts among transsexuals." |xix In New York, two cases in the ig7os held that the plaintiffs who desired coverage of SRS under Medicaid had failed to prove the medical necessity of the treatment, ${ }^{\mathrm{kxx}}$ and now New York continues to proscribe coverage for anything related to gender reassignment, includ. ing hormone therapy. lxxi

Slowly, cases have arisen that challenge the acceptability of categorical denial of procedures relating to GID. In Minnesota, Doe v. State Department of Public Welfare held that the standards the state was using were so high as to be burdensome for patients, and that the state had to consider funding future applications for transsexual surgery. lxxii In Massachusetts, which currently bans all SRS-related procedures, the state was ordered to pay for breast reconstruction for a trans-woman who had had SRS 25 years ago and whose silicone implants were leaking. ${ }^{\mid x x i i i}$ While this does not reverse the ban, it does provide some hope for transgender persons that progress is being made to raise awareness regarding this issue.

\section{PROSCRIPTION OF SRS: DISCRIMINATION \\ IN PUBLIC POLICY?}

This paper has argued that the process of completing gender transition is very involved and closely regulated by medical professionals. Therefore, the decision to undergo SRS cannot be considered a whimsical decision made by a disturbed individual and instead must be regarded as a lifechanging choice that is made with the assistance of experts 
in order to treat a psychological condition. It cannot be considered cosmetic or experimental, and is medically necessary. Categorical denial of funding for treatment of transgender individuals is inappropriate and unethical, because it constitutes discrimination based on a specific type of illness. This is forbidden by the Medicaid statutes, as it is prejudiced against a group of people. Denial of services because of cost is a specious argument because there is a very low percentage of transgender persons, so no significant monetary loss would occur from allowing coverage for SRS. In addition, providing funding for treatment could decrease costs associated with long-term effects of untreated GID, such as depression, anxiety, and dangerous consequences of illegal hormone use. Finally, since there is no formula presented by the federal government for making evaluations of claims, they should be made on a case-by-case basis, as Finley suggests, taking into account the goals of Medicaid, the best interest of the patients, and the fiscal needs of the state. lxxiv

The fact that cases are still ruled in favor of state proscriptions is, in most cases, a reflection of misunderstanding and discrimination in our society. When claims made by transgender persons are treated with the same reasonableness that is extended to other claims, a part of this institutionalized prejudice will cease to exist. Unfortunately, the prejudice extends to the very top; transgender individuals who attempt to take recourse cannot apply to the Americans with Disabilities Act (ADA). In I990, Congress specifically excluded transgender persons from protection under the act, putting them in a category of other excluded groups such as pedophiles, voyeurs, and pyromaniacs, ${ }^{\text {,xxy }}$ despite the fact that transgender individuals are also said to have a non-criminal psychological condition as defined by DSM-IV. This discrepancy reflects a fear and willful ignorance of transsexuality and transgender issues that is clearly unethical and harmful to the very citizens the government is ostensibly trying to protect. This is particularly detrimental to transgender persons who have private health insurance, because when they are denied by their providers they have few options for recourse if they cannot claim discrimination based on ADA.

\section{EPILOGUE: NEW AMA REGULATIONS AND}

\section{THE FUTURE OF INSURANCE FUNDING}

In June 2007, The American Medical Association voted to amend its nondiscrimination policies to include transgender people. This new policy specifically states the AMA's opposition to "the denial of health insurance on the basis of sexual orientation or gender identity." |xxvi The influence of the AMA's increasingly high-profile stance on gay, lesbian, and transgender issues is causing many healthcare insurers and municipalities across the United States to reexamine their policies to ensure that transgender patients are not denied access to medically necessary services. In 2001 , San

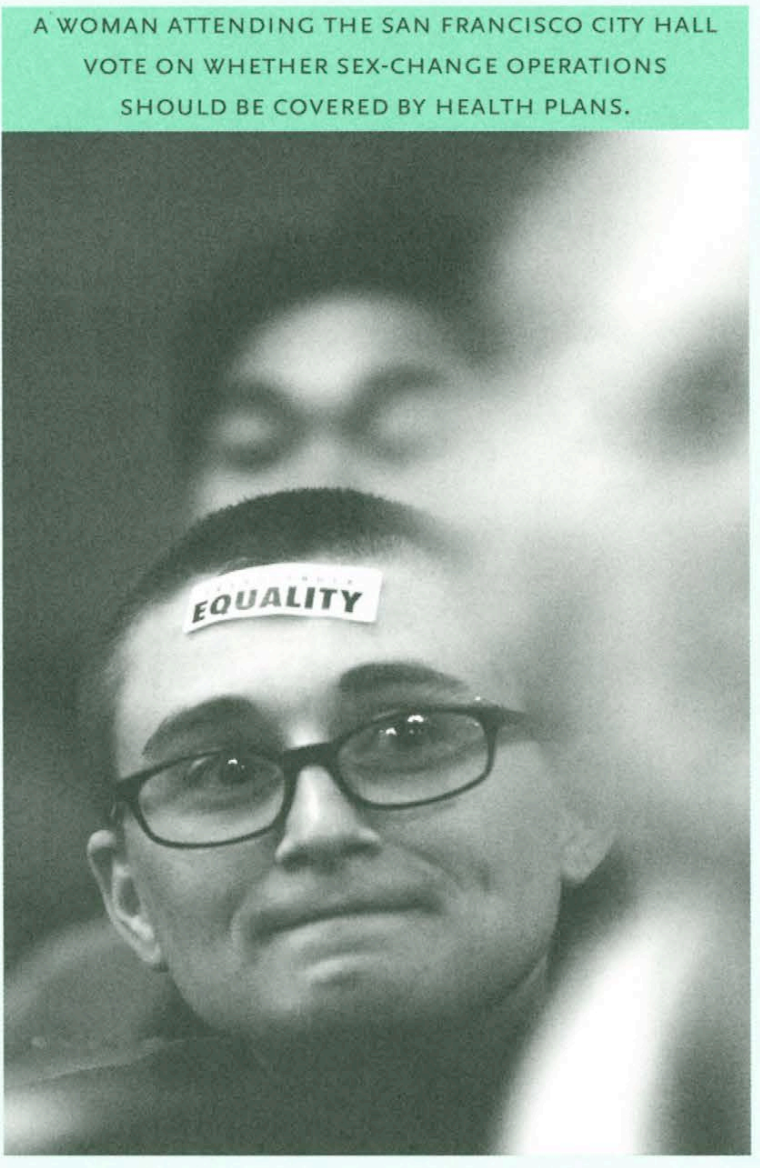


Francisco became the first city to pay for SRS for its workers, and Berkeley will most likely follow soon. lxxvii The AMA's amendment of its nondiscrimination policies will perhaps provide an example for private insurance companies and federal and state governments in order that the categorical exclusion of members of society can cease to be a reality.

\section{ENDNOTES}

i. Sultan (2003)

ii. Savage

iii. "Inpatient Care Exclusions, Aetna HMO Summary Plan Description 2007" (2007)

iv. The Harry Benjamin International Gender Dysphoria

Association's Standards of Care For Gender Identity Disorders (2001)

v. Diagnostic and Statistical Manual of Mental Disorders (2007)

vi. Sultan (2003)

vii. Standards of Care (200I)

viii. Sultan (2003)

ix. Ladrach (1987)

x. Kv. Health Division, Dept. of Human Resources (1976)

xi. Massachusetts General Laws (200I)

xii. Harris (I997)

xiii. Dasti (2002)

xiv. Innes Bowen (2000)

xv. Standards of Care (200I)

xvi. $\operatorname{SOC}(200 \mathrm{I})$

xvii. SOC (200I)

xviii. Ibid.

xix. $S O C(2001)$

$x x \cdot \operatorname{SOC}(200 \mathrm{I})$

xxi. $S O C(2001)$

xxii. SOC (2001)

xxiii. Sultan (2003)

xxiv. $S O C(200 I)$

xxv. SOC (200I)

xxvi. Sultan (2003)

xxvii. SOC (200I)

xxviii. SOC (200I)

xxix. Savage

xxx. Sultan (2003)

xxxi. "Female to Male Transsexuals" (2007)

xxxii. SOC (200I)

xxxiii. Sultan (2003)

xxxiv. SOC (200I)

xxxv. SOC (200I)

xxxvi. "Medicare History" (2000)

xxxvii. For groups fighting for Medicare rights for transsexuals, see www.gendercare.org

xxxviii. Finley (I978) xxxix. Ibid.

xl. Ibid,

xli. Ibid.

xlii. Ibid.

xliii. Hall (1992)

xliv. Hall (1992)

xlv. Hall (1992)

xlvi. Finley (1978)

xlvii. Ibid.

xlviii. Ibid.

xlix. Ibid.

1. Savage

li. Dasti (2007)

lii. G. B. v. Lackner (1978)

liii. Kirkland (2003) pI7

liv. Rush v. Parham (1980). SRS was invented in I9 65. By i9 80 ,

the doctor in the case claims, several thousand patient had un-

dergone the procedure.

lv. Kv. Health Division (1976)

lvi. $\operatorname{SOC}(200 \mathrm{I})$

lvii. SOC (200I)

lviii. Sultan (2003)

lix. Dasti (2007)

lx. Dasti (2007)

1xi. Doe v. Minnesota Department of Public Welfare and Hennepin County Welfare Board (1977)

lxii. Finley (1978)

Ixiii. Savage

lxiv. Savage

lxv. "AMA expands non-discrimination policy" (2007)

lxvi. Sultan (2003)

lxvii. Pinneke v. Preisser (1980

lxviii. Smith v. Ramussen (200I)

lxix. Savage

lxx. Dasti (2007)

lxxi. Sultan (2003)

lxxii. Doe v. State, Dept. of Public Welfare (1977)

lxxiii. Beger v. Acting Comm'r, Div. of Med. Assistance (2000);

Sultan (2003)

lxxiv. Finley (1978)

lxxv. Kirkland (2003)

lxxvi. "AMA expands non-discrimination policy." (2007)

lxxvii. "San Francisco First City to Pay for City Workers' Sex

Changes" (200I)

\section{REFERENCES}

"AMA expands non-discrimination policy." 3 July 2007.

Gaywired.com. Io Nov, 2007, <www.gaybusinessworld.com>.

"AMA expands non-discrimination policy." Gay Business World. 3 July 2007.

Beger v. Acting Comm'r, Div. of Med. Assistance, II Mass. L. Rptr. No. 3I, 745, 747 (Mass. Super. Ct. May I, 2000); Sultan, I206. 
Diagnostic and Statistical Manual of Mental Disorders, Fourth Edition (DSM-IV). As provided by AllPsych Online, <www.allpsych.com/disorders/sexual/genderidentity.html>. 15 May 2007, Accessed 4 December 2007.

Doe v. Minnesota Department of Public Welfare and Hennepin County Welfare Board, 257 N.W.2d 816, 819 (Minn.1977)

"Exclusions and Limitations, Blue Cross Blue Shield of Arizona." <http://www.azblue.com/healthplans/under65/exclusions_limitationsi.asp >. Accessed 4 December 2007.

"Female to Male Transsexuals," from California's gender health site, Updated I5 Aug. 2007. <http://www.genderandhealth.ca/ en/modules/sexandsexuality/gss-transgendered-issues-O2.jsp> Accessed 5 December 2007.

Finley, Lucinda M. November 1978. "State Restrictions on Medicaid Coverage of Medically Necessary Services." Columbia Law Review, Vol. 78, No. 7, pp. I491-1516.

G. B. v. Lackner, 145 Cal.Rptr. 555, 80 Cal.App.3d 64 (Cal.App. . Dist., 1978)

Hall, Mark A. and Gerald F. Anderson. May 1992. "Health Insurers' Assessment of Medical Necessity." University of Pennsylvania Law Review, Vol. I40, No. 5. pr645-1646.

Harris, In re, 707 A.2d 225 (Pa. Super., I997)Dasti, Jerry L. "Sex Reassignment Under Medicaid." New York University Law Review. 24 December 2002. pI773.

The Harry Benjamin International Gender Dysphoria Association's Standards of Care For Gender. Identity Disorders, Sixth Version. February 2001. p2, 22.

Innes Bowen "Are Sex Change Operations Justified?" $B B C$ News. I August 2000.

"Inpatient Care Exclusions, Aetna HMO Summary Plan Description 2007," p3I.

Kv. Health Division, Dept. of Human Resources, 552 P.2d 840, 26 Or.App. 3 II (Or. App., 1976).

Kirkland, Anna. 2003. "Victorious Transsexuals in the Courtroom: A Challenge for Feminist Legal Theory." American Bar Association. pI7.

Ladrach, In re, 513 N.E.2d 828831 (Ohio P. Ct. 1987).

Massachusetts General Laws, ch. 46, ( I3(e) (2001).
"Medicare History" Medicare Rights Center. Updated 2 August, 2000. <http://www.medicarerights.org /maincontenthistory.html>. Accessed 6 December 2007.

Pinneke v. Preisser, 623 F.2d 546 (C.A.8 (Iowa), 1980).

"Required Outline of Coverage, Blue Cross Blue Shield Texas," p7., etc.

Rush v. Parham 625 F.2d 1150 (C.A.5 (Ga.), 1980). SRS was invented in 1965 . By 1980 , the doctor in the case claims, several thousand patient had undergone the procedure.

"San Francisco First City to Pay for City Workers' Sex Changes," The Chicago Tribune. oI May. 2001.

Savage, Todd. "Costly Trans-action- high cost of sex-change operations."

Sultan, Bradley. "Transsexual Prisoners." The New England Law Review, 20 May 2003, pII97, 1203. 